6. Алексенцева, С.Е. Методика оценки типа и степени износа, влияющего на эксплуатационную надёжность и рыночную стоимость нарезного оружия в гражданском секторе [Текст] / С.Е. Алексенцева, И.В.Захаров - М.: Технология металлов - 2021.- N6. -C.49-54.

7. Алексенцева, С.Е. Процессы кинетики, деформации и разрушения при высокоскоростном ударе и бронепробитии. Уч.пособие. [Текст] / С.Е. Алексенцева - Самара: РИО СамГТУ.- 2-е изд.-2017. 98 c. ISBN 978-5-7964-2052-2

8. Алексенцева, С.Е. Особенности траектории торможения пули в тормозной среде при контрольном отстреле огнестрельного оружия [Текст] / С.Е. Алексенцева - 2020. -Смоленск: Наукосфера №12(2) -C.128-133

\title{
Песков А.В. \\ Эффективность применения схемы импульсной легирующей обработки с целью повышения стойкости бурильного инструмента для нефтяных и газовых скважин
}

Самарский государственный технический университет (Россия, Самара)

doi: $10.18411 / / j-07-2021-27$

\section{Аннотация}

Исследована эффективность применения импульсной легирующей обработки в виде расширяющегося высокоскоростного потока порошковых частиц для повышения стойкости бурильного инструмента при бурении нефтяных и газовых скважин.

Ключевые слова: бурильный инструмент, нефть, схема импульсной обработки, поток частиц, микролегирование, стойкость.

\section{Abstract}

There is operational effectiveness of pulsing treatment in the form of a dilated highvelocity flow of particles for stability of drilling tool at boring of oil and gas wells.

Keywords: drilling tool, oil, plan of explosive treatment, stream of particles, microdoping, stability.

Научные разработки в инструментальной отрасли наиболее широко представлены в области получения новых материалов в соответствии со спецификой использования их для конкретных инструментов и предназначены в основном для решения проблем упрочнения, износостойкости, приводящие к повышению работоспособности инструментов, повышению их стойкости [1]. Изготовление заготовок инструментов производится металлургическими способами с применением легированных материалов и последующей обработкой поверхности инструментов.

Актуальным направлением так же является дополнительная упрочняющая обработка специально подобранных материалов заготовок инструментов. Наиболее перспективными видами данной обработки являются импульсные и плазменные методы, лазерное упрочнение и легирование, взрывные технологии, обработка с применением воздействия внешних импульсов упрочняющих объектов и др.

Подбор упрочняющей технологии связан со спецификой области применения, условий работы и конструкции инструмента. Бурильный инструмент при добыче нефти и разработке газовых месторождений имеет сложную конструкцию. Для бурения твёрдых пород - это фрезерные и трёхшарошечные долота с шарошкой, работающей в условиях ударных нагрузок. Так, бурильные инструменты при нефте- и газовой добыче должны иметь высокую прочность в условиях системы внешних ударных силовых воздействий, причём справедливы требования по вязкой составляющей материалов. В условиях непрерывной многочасовой истирающей нагрузки инструменты должны иметь высокую износостойкость поверхности [1,2]. 
Данная работа предлагает использовать направление по обеспечению необходимых прочностных характеристик инструмента за счёт использования импульсной обработки заготовки методом воздействия потока высокоскоростных частиц, метаемых энергией взрыва [3]. В качестве заготовки предложено использовать вольфрамокобальтовые быстрорежущие инструментальные стали Р9К5, РМ4К8 и P6М5К5(5.7-6.7\%W, 4.8-5.3\%Мo, 4.7-5.2\%Сo) [4]. В результате данной обработки высокоскоростным потоком порошковых частиц размером 10-100 мкм, метаемых со скоростью 1-3 км/с, происходит проникание частиц на глубину порядка тысячи их исходных размеров ударников. При метании частиц никеля, вольфрама, хрома, железа, карбида хрома, карбонитрида титана получены объёмно-легированные материалы с высокими прочностными характеристиками. Реализуется повышение прочностных параметров материалов в объёме проникающих частиц на глубине до десятков миллиметров, обеспечивается повышение износостойкости $[3,4]$. Упрочняющий эффект достигается за счёт появления микроканалов в процессе проникания частиц, формирования пластически деформированной структуры и армирования микроканалов [5-7].

Изначально в работах [3,8] для метания частиц были использованы кумулятивные ускорители различной конструкции с различными типами кумулятивных выемок. В соответствии с механизмом образования кумулятивной струи поток высокоскоростных частиц формируется на фокусном расстоянии, которое соотносится с минимальным расстоянием заряда от преграды, при котором кумулятивный пробивающий эффект максимален. Глубина пробития достигается на оптимальном фокусном расстоянии от преграды, которое изменяется в зависимости от конструкции заряда, материала облицовки, в данном случае от физических параметров порошка. Функции кумулятивной облицовки выполняет слой частиц, расположенных в кумулятивной выемке [9]. Происходит перераспределение энергии между продуктами детонации энергонасыщенных материалов (ЭНМ) и материалом частиц. Идёт переход части материала в кумулятивной выемке в кумулятивную струю. Основная часть энергии активной части кумулятивного заряда концентрируется в слое порошковых частиц, формируя высокоскоростной поток. Формируется большая плотность энергии в потоке частиц.

Кумулятивные эффекты при формировании высокоскоростного потока частиц приводят к интенсивному кратерообразованию на поверхности обрабатываемого материала. Имеется ударное размывание и вынос материала. Взрывной ускоритель с конической кумулятивной выемкой показан на рис.1. С помощью детонатора - 1 производится инициирование заряда - 2. Навеска порошка находится внутри кумулятивной выемки - 3. При использовании данной схемы взрывного ускорителя получаем высокоскоростной поток, параметры которого зависят от массы и диаметра заряда, параметров кумулятивной выемки. Использование зарядов большой массы и мощности приводит к необходимости увеличения массы навески порошка, что не эффективно, т.к. приводит к значительным потерям порошковой навески.

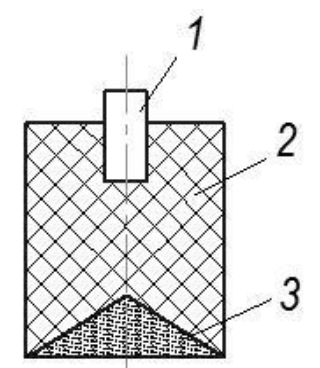

Рис.1. Схема ускорителя с кумулятивной выемкой, 1 - детонатор, 2 - заряд ЭНМ, 3 - навеска порошка 
Создана схема обработки повышенной эффективности при однократном воздействии на материалы за счёт увеличения равномерности плотности и площади обстрела струёй дискретных частиц [10]. Данную установку предлагается применить для обработки заготовок вольфрамо-кобальтовых сталей бурильных инструментов для разработки нефте- и газовых скважин.

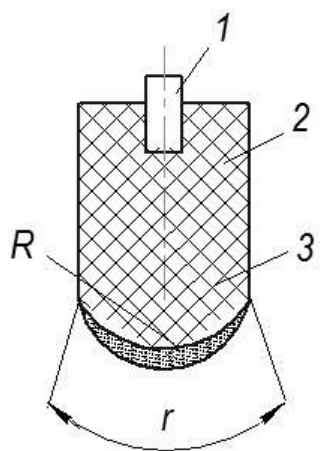

Рис.2. Схема ускорителя с максимальным охватом площади обработки, 1 - детонатор, 2 - заряд ЭНМ, 3 -метаемый порошок

В данной схеме ускорителя частиц (рис.2) заряд ЭНМ конструктивно представляет цилиндр, нижняя часть которого имеет форму сферического сегмента с радиусом R. На сферическую поверхность наносят метаемый слой порошковых частиц. Инициирование заряда осуществляется с помощью электродетонатора - 1. После инициирования заряда - 2 формируется метательный конус потока высокоскоростных частиц - 3 с радиусом раствора $r$ равномерной плотности и максимальной площадью обстрела за счёт применения в конструкции сферической поверхности [10]. При этом реализуется сверхглубокое проникание частиц и объёмное микролегирование заготовки инструмента [11-12] .

Таким образом, предлагается для импульсной объёмно-легирующей обработки с целью повышения стойкости и эксплуатационной надёжности бурильного инструмента для нефтяных и газовых скважин использовать эффективную импульсную схему обработки, основанную на взрывном метании порошковых частиц в виде расширяющегося конуса.

$$
* * *
$$

1. Мингазов, Р.Р. Долота для бурения по твёрдым породам [Текст] /Р.Р.Мингазов, А.М.Шарипов. М.:Бурение и нефть. - 2012.- №12.- С46-48.

2. Коршунов, Л.Г. Влияние воздействия ускоренного взрывом потока частиц $\mathrm{SiC}$ на микроструктуру и трибологические свойства износостойкой хромомарганцевой метастабильной аустенитной стали / Л.Г.Коршунов, С.М.Ушеренко, Н.Л.Черненко, О.А.Дыбов // ФММ. - 2005.- Т.100. - N3. - С.95103.

3. Ушеренко, С.М. Сверхглубокое проникание частиц в преграды и создание композиционных материалов [Текст] / С.М. Ушеренко. - Минск: НИИ Импульсных процессов. - 1998. - 210 с.

4. Марочник стали и сплавов [Текст]. 4-е изд. Под общей редакцией Ю.Г.Драгунова и А.С.Зубченко / Сост. Драгунов Ю.Г., Зубченко А.Г., Каширский Ю.В., Дегтярёв А.Ф., Жаров В.В., Колосов М.М., Орлов А.С., Скоробогатых В.Н. - М.:2014.-1216 с.

5. Ушеренко, С.М. Современные представления о комплексе физических эффектов в условиях сверхглубокого проникания [Текст]/ С.М.Ушеренко, А.С.Калиниченко, К.И.Чой, В.И.Овчинников // Труды международной конференции «VII Харитоновские тематические научные чтения» Саров, 14-18 марта. - 2005.- C.520-526.

6. Алексенцева С.Е., Кривченко А.Л. Исследование особенностей обработки металлов и сплавов высокоскоростным потоком дискретных частиц, разогнанных энергией взрыва канальных зарядов и другими динамическими методами [Текст] / Вестник СамГТУ. Серия "Технические науки". 2013.- N2(38). - C.71-78. 
7. Алексенцева, С.Е. Дисперсноупрочнённые материалы для биомедицины, полученные обработкой высокоскоростным потоком дискретных частиц, разогнанных энергией взрыва [Текст]/ С.Е.Алексенцева // Образование. Наука. Научные кадры. -2015.- №2.- С.250-253.

8. Андилевко, С.К. Осесимметричный взрывной ускоритель с конической выемкой, заполненной порошком [Текст]/ С.К.Андилевко, О.А.Дыбов, О.В.Роман // ИФЖ. - 2000. - Т.73. - N4. - C.797801.

9. Физика взрыва [Текст]/ Под ред. Л.П.Орленко. - Изд. 3-е, переработанное. - В 2-х томах - Т.1.-М.: ФИЗМАТЛИТ, 2002. - 656 с.

10. Алексенцева, С.Е. Повышение эффективности обработки материалов потоком высокоскоростных дискретных частиц [Текст] / С.Е. Алексенцева. - Вестник СамГТУ. Серия "Технические науки". - 2015.- N1(45). - С.142-145.

11. Алексенцева, С.Е. Упрочнение сварного шва рельсового стыка [Текст] /С.Е.Алексенцева. Вестник СамГТУ. Серия "Технические науки". - 2016.- N1(49). - С.130-137.

12. Алексенцева, С.Е. Взрывное микролегирование и упрочнение потоком высокоскоростных частиц сварных швов рельсовых стыков и конструкций [Текст] / С.Е. Алексенцева, И.В. Захаров. Технология металлов. - 2018. - N10. - С.18-24. 